\title{
Neuronal and endothelial nitric oxide synthase expression in outer medulla of streptozotocin-induced diabetic rat kidney
}

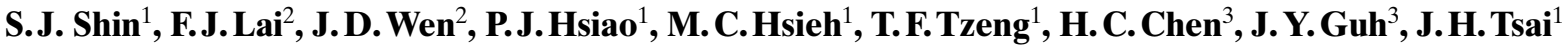 \\ ${ }^{1}$ Division of Endocrinology and Metabolism, Kaohsiung Medical University, Kaohsiung, Taiwan \\ ${ }^{2}$ Graduate Institute of Medicine, Kaohsiung Medical University, Kaohsiung, Taiwan \\ ${ }^{3}$ Division of Nephrology, Kaohsiung Medical University, Kaohsiung, Taiwan
}

\section{Abstract}

Aims/hypothesis. Several investigations have shown that the renal medulla has a greater capacity to generate nitric oxide than the renal cortex. To further evaluate the changes of nitric oxide synthesis in the kidney, particularly in the outer medulla, in disorders involving fluid and electrolyte imbalances, we sought to determine renal nitric oxide synthase expression in the diabetic rats.

Methods. We determined renal nitric oxide synthase mRNA and urinary nitrite/nitrate excretion in 12 normal and 12 streptozotocin-induced diabetic rats by reverse transcription-polymerase chain reaction with Southern blot hybridization and with Griess reaction, respectively. Nitric oxide synthase immunoreactivity was detected by immunohistochemistry in four normal and four diabetic rats.

Results. Neuronal and endothelial nitric oxide synthase mRNA were 3.5-fold and 1.8-fold increased in the outer medulla of 12 diabetic rats with no difference found in the cortex and inner medulla when compared with 12 normal rats. Urinary nitrite/nitrate excretion was significantly increased from the first week after diabetic induction. In normal rats, immunohistochemical studies showed positive neuronal and endothelial nitric oxide synthase immunostaining in almost all segments of renal tubules. Diabetic rats had the greatest enhancement of immunostaining for neuronal and endothelial nitric oxide synthase in the proximal straight tubule and medullary thick ascending limb.

Conclusion/interpretation. Our results indicate that increases in neuronal and endothelial nitric oxide synthase synthesis in the kidney, particularly in the outer medulla, possibly play an important part in the adaptation of renal function to hyperglycaemia and hyperosmolality in diabetes. [Diabetologia (2000) 43: 649-659]

Keywords Nitric oxide, neuronal nitric oxide synthase, endothelial nitric oxide synthase, diabetic kidney, outer medulla, renin, angiotensinogen.
Received: 5 October 1999 and in revised form: 20 January 2000

Corresponding author: Dr S. J. Shin, Division of Endocrinology and Metabolism, Kaohsiung Medical University, 100 ShihChuan 1st Rd. Kaohsiung 80708, Taiwan

Abbreviations: NO, Nitric oxide; eNOS, endothelial nitric oxide synthase; nNOS, neuronal nitric oxide synthase; ANP, atrial natriuretic peptide; PCT, proximal convoluted tubule; PST, proximal straight tubule; TL, thin limbs of Henle's loop; MTAL, medullary thick ascending limb; DCT, distal convoluted tubule; CCD, cortical collecting duct; OMCD, outer medullary collecting duct; IMCD, inner medullary collecting duct.
Several studies have shown that the intrarenal synthesis of vasodilators, including prostaglandin [1], kinin [2] and atrial natriuretic peptide (ANP) [3], are increased in diabetic rats and it has been proposed that this increase is responsible for the glomerular hyperfiltration in such rats. Similarly, increased renal nitric oxide (NO) activity, as assessed by urinary excretion of nitrites and nitrates, has also been reported in experimental diabetes [4-9]. Apart from the measurement of urinary nitrite/nitrate $\left(\mathrm{NO}_{2}^{-} / \mathrm{NO}_{3}^{-}\right)$concentrations, very little is known about the levels of NO synthase (NOS) mRNA or protein in the kidney of diabetic rats. An increase of endothelial NO syn- 
thase (eNOS) expression in afferent arterioles and glomeruli of diabetic rat kidneys was reported [9], whereas decreased neuronal NOS (nNOS) immunoreactivity was found in macula densa [10]. In another study of diabetic rats, it was found that nNOS, eNOS and inducible NOS (iNOS), determined by Western blot analysis, were all increased in the renal cortex, whereas they remained unchanged in the renal medulla [11]. A large number of studies, however, have shown that the renal medulla has a greater capacity to generate NO than the renal cortex [12-17]. Using reverse transcription-polymerase chain reaction (RT-PCR), several investigators have shown the presence of the highest nNOS mRNA in the inner medullary collecting duct (IMCD) [15] and iNOS mRNA in the medullary thick ascending limb (MTAL) and IMCD [16, 17], with lesser expression in other nephron segments. In the kidney, NO has been shown to have a homeostatic regulation on renal tubular, glomerular and vascular functions [18-21]. In addition to abnormalities in glomerular haemodynamics, early stages of diabetic nephropathy are actually also associated with alterations in renal tubular function [6]. It is therefore possible that synthesis of NOS could be strongly related to the changes of renal tubular functions as well as glomerular haemodynamics in diabetes. In other words, the alteration of NO production in the renal tubule could modulate renal tubular function in diabetes. To investigate the responsiveness of NOS synthesis in the kidney, particularly in the medulla, to disorders of fluid imbalance, we characterised the changes in the expression of renal nNOS and eNOS mRNA and protein in streptozotocin-induced diabetic rats by RTPCR coupled with Southern blot hybridisation and immunohistochemistry.

\section{Materials and methods}

Animal experiments. Male Wistar rats, (produred from National Cheng Kung University, Taiwan) weighing 250 to $280 \mathrm{~g}$ were individually housed in metabolic cages. Diabetes was induced by a single peritoneal injection of $55 \mathrm{mg} / \mathrm{kg}$ streptozotocin (Sigma Chemical, St. Louis, Mo., USA). Twenty-four hours later, induction of diabetes was confirmed by measuring their tail blood glucose concentrations (Accutrend Glucose, Boehringer Mannheim, East Sussex, UK). Rats with blood glucose concentrations greater than $19.4 \mathrm{mmol} / \mathrm{l}$ were included. Diabetic rats received ultralente insulin (Novo-Nordisk, Copenhagen, Denmark) designed to achieve blood glucose concentrations between 19.4 and $33.3 \mathrm{mmol} / \mathrm{l}$. We studied 16 body weight and age-matched rats as normal control animals. In experiment 1,12 normal and 12 diabetic rats were killed and blood was collected to measure plasma angiotensin II, ANP, arginine vasopressin, sodium and osmolality on day 42 after streptozotocin or citric buffer injection. The right kidneys were immediately removed and separated into cortex, outer and inner medulla for nNOS, eNOS, renin, angiotensinogen and $\beta$-actin mRNA analysis. Left kidneys were extracted to determine an- giotensin II content. Urine sodium, glucose, and osmolality were measured on the 42nd day, whereas urine $\mathrm{NO}_{2}^{-} / \mathrm{NO}_{3}{ }^{-}$excretion rate were measured on day $0,7,14,21,28,35$ and 42 in the two groups. In experiment 2 , on day 42 four normal and four diabetic rats were anaesthetised with sodium pentobarbital (Abbott Laboratories, Chicago, Ill., USA) and infused with normal saline by way of the left cardiac ventricle and then with phosphate buffer solution ( $\mathrm{pH} 7.4$ ) containing $4 \%$ paraformaldehyde for $15 \mathrm{~min}$. Kidneys were removed and immersed in $4 \%$ paraformaldehyde for $2 \mathrm{~h}$. Thin kidney slices, which included the cortex, outer and inner medulla of normal and diabetic rats, were embedded within the same paraffin block and cut into $4 \mu \mathrm{m}$ sections for immunohistochemical study. This study was approved by the Animal Care and Treatment Committee of Kaohsiung Medical University.

$R N A$ isolation and reverse transcription. Total RNA was extracted from the renal cortex, outer and inner medulla using a modified guanidium isothiocyanate method [22]. Two $\mu \mathrm{g}$ of total RNA from the renal cortex, outer and inner medulla were reverse transcribed by incubation with $20 \mu$ l reverse transcription mixture containing: 20 pmol oligo $(\mathrm{dT})_{18}$ primer, $50 \mathrm{mmol} / \mathrm{l}$ TRIS-HCl (pH 8.3), $75 \mathrm{mmol} / \mathrm{l} \mathrm{KCl}, 3 \mathrm{mmol} / \mathrm{l}$ $\mathrm{MgCl}_{2}, 30$ units of RNase inhibitor, $0.5 \mathrm{mmol} / \mathrm{l} \mathrm{dNTPs}$, and 50 $\mathrm{U}$ of MMLV reverse transcriptase (Stratagene Laboratories, Palo Alto, Calif., USA) at $37^{\circ} \mathrm{C}$ for $2 \mathrm{~h}$. The reverse transcriptase was inactivated by heating for $5 \mathrm{~min}$ at $94^{\circ} \mathrm{C}$.

Polymerase chain reaction amplification and Southern blot hybridization. Polymerase chain reaction was carried out at a final concentration of $1 \times \mathrm{PCR}$ buffer $(10 \mathrm{mmol} / \mathrm{l} \mathrm{TRIS}-\mathrm{HCl}$, $\left.\mathrm{pH} 8.3,50 \mathrm{mmol} / \mathrm{l} \mathrm{KCl}, 1.5 \mathrm{mmol} / \mathrm{l} \mathrm{MgCl}_{2}\right), 0.2 \mathrm{mmol} / \mathrm{l} \mathrm{dNTPs}$, $0.4 \mu \mathrm{mol} / \mathrm{l}$ sense and antisense oligos, 2.0 units of Taq DNA polymerase (Boehringer Mannheim, Indianapolis, Ind., USA) to a total volume of $50 \mathrm{\mu l}$. The amplifications were done for $45 \mathrm{~s}$ at $94^{\circ} \mathrm{C}, 45 \mathrm{~s}$ at $60^{\circ} \mathrm{C}$ and $90 \mathrm{~s}$ at $72^{\circ} \mathrm{C}$ in a PerkinElmer Cetus 9600 thermocycler (Perkin-Elmer Cetus, Norwalk, Conn., USA). Sense primers for nNOS were 5'-GA ATACCAGCCTGATCCATGGAA-3' corresponding to bp 2461-2483, and antisense primers were 5 '-TCCAGGAGGGTGTCCACCGCATG-3' corresponding to bp 3037-3059, which yielded a 599 bp PCR product. Sense primers for eNOS were 5'-TACGGAGCAGCAAATCCA C-3', and antisense primers were 5'-GATCAAAGGACTGCAGCCTG-3', which yielded an 819 bp PCR product [23]. Sense primers for renin were 5 '-TGGGTGCCCTCCACCAAG T-3' corresponding to bp 540-558, and antisense primers were 5 '-TCCCAGGGCTTGCATGATCA-3' corresponding to bp 1120-1139; which yielded a $600 \mathrm{bp}$ PCR product. Sense primers for angiotensinogen were 5'-CAACACCTACGTTCACTTCC-3' corresponding to bp 867-886; and antisense primers were $5^{\prime}-\mathrm{GAG}$ TTCAAGGAGGATGCTGT-3' corresponding to bp 1310-1330; which yielded a 464 bp PCR product. Sense primers for $\beta$-actin were 5'-CGTAAAGACCTCTATGCCAA-3' corresponding to bp 2750-2769, and antisense primers were 5 '-AGCCATGCCAAATGTCTCAT-3' corresponding to bp 3203-3222, which yielded a 349 bp PCR product. The amplification cycles of the PCR procedure were evaluated for NOSs, renin, angiotensinogen and $\beta$-actin mRNA. The amplification cycles of all following PCR analyses were selected only during the exponential phase. The amplification cycles were repeated 24, 22 and 22 times for nNOS, and eNOS mRNA, but 20, 22, and 24 for renin and angiotensinogen mRNA in the renal cortex, outer medulla, and inner medulla, respectively.

From each PCR production, the amplified products were electrophoresed on $1.5 \%$ agarose gels and transferred to nylon 
membranes (Schleicher \& Schuell, Dassel, Germany). The blots were hybridised with $\left[{ }^{32} \mathrm{P}\right]$ labelled randomly-primed rat nNOS, eNOS, renin, and angiotensinogen cDNA prepared by PCR cloning for $16 \mathrm{~h}$ at $37^{\circ} \mathrm{C}$ according to the standard technique. After each hybridization, the blots were washed twice in a solution containing $0.1 \%$ sodium dodecyl sulfate (SDS) and $2 \times \mathrm{SSC}(0.3 \mathrm{~mol} / 1 \mathrm{NaCl}, 30 \mathrm{mmol} / 1$ sodium citrate $)$ for $15 \mathrm{~min}$ at room temperature and then twice in $0.1 \%$ SDS and $0.1 \times \mathrm{SSC}$ at $65^{\circ} \mathrm{C}$. Blots were exposed to Kodak BIOMAXMR (Eastman Kodak Company, Rochester, N. Y., USA) film at $-70^{\circ} \mathrm{C}$. A radioisotope-labelled probe for $\beta$-actin used as an internal control was also made using the primer extension method. After autoradiography, the x-ray film was scanned by a laser densitometer and the data were analysed by MD ImageQuant software release version 3.22 (Molecular Dynamics, Sunnyvale, Calif., USA). To determine the relative changes in tissue NOS mRNA expression, the yield of NOS PCR products were normalized to the amount of $\beta$-actin cDNA amplified from the same RT cDNA of tissue samples, a method that has been used in our previous reports $[3,17,24]$ and in other studies [23]. The accuracy of the semiquantitative RT-PCR with Southern blot analysis in this study was tested. Serial dilution $(0.4,0.8,1.2,1.6,2.0$ and $2.4 \mu \mathrm{g})$ of total RNA was subjected to RT-PCR amplification for eNOS, nNOS, renin, angiotensinogen and $\beta$-actin mRNA. The correlation coefficients between RNA concentrations and corresponding densities for eNOS, nNOS, renin, and angiotensinogen mRNA were $r=0.962, r=0.970, r=0.963$, and $r=0.961$ from renal cortex, and $r=0.958, r=0.967, r=0.959$, and $r=0.953$ from outer medulla, and $r=0.960, r=0.972, r=0.963$ and $r=0.962$ from inner medulla, respectively. An intra-assay test of RT-PCR followed by Southern blot analysis in $2.0 \mu \mathrm{g}$ total RNA extracted from renal tissues was done. The variation coefficients of the intra-assay test for eNOS, nNOS, renin, and angiotensinogen mRNA were $4.8 \%, 5.7 \%, 6.8 \%$, and $6.3 \%$ from the renal cortex $(n=8) ; 7.1 \%, 6.0 \%, 6.3 \%$, and $6.6 \%$ from the renal outer medulla $(n=8)$; and $6.8 \%, 6.3 \%, 5.8 \%$, and $6.2 \%$ from the inner medulla $(n=8)$ of normal rat renal tissues, respectively. To assess the inter-assay variations, 10 normal samples with the same RNA doses as determined by spectrophotometer and near equal densities on the agarose gel electrophoresis, were processed for RT-PCR followed by Southern blot hybridization. The variation coefficients of inter-assay test were 5.9 to $9.0 \%$, and 6.2 to $8.7 \%$ for nNOS and eNOS, respectively. The relative levels for nNOS, eNOS, renin and angiotensinogen mRNA between renal cortex, outer medulla and inner medulla from 12 normal rats were also assessed by RT-PCR followed with Southern blot hybridisation. The cycles of PCR amplification were repeated 22 times for nNOS, eNOS, renin and angiotensinogen mRNA.

Immunohistochemistry. Immuohistochemistry was done with microwave heating as described [25]. Briefly, after deparaffinization and rehydration, sections were placed in $0.01 \mathrm{~mol} / 1$ sodium citrate buffer ( $\mathrm{pH}$ 6.0) and heated twice in a microwave oven for $5 \mathrm{~min}$ at $720 \mathrm{~W}$. After microwave treatment, sections were washed in PBS and incubated with $1 \%$ bovine serum albumin for $30 \mathrm{~min}$ to block nonspecific staining. Sections were drained and incubated for $3 \mathrm{~h}$ at room temperature in a humidity chamber with the respective rabbit anti-nNOS serum (1:1000 dilution), mouse anti-eNOS serum (1:1000), primary antibody (Calbiochem-Novabiochem Corporation, San Diego, Calif., USA) diluted with antibody diluent (Dako; Glostrup, Denmark). After washing in PBS, endogenous peroxidase activity was blocked by incubation in $0.3 \% \mathrm{H}_{2} \mathrm{O}_{2}$ in methanol for $20 \mathrm{~min}$, followed by sequential $10 \mathrm{~min}$ incubations with biotinylated link antibody and peroxidase-labelled streptavidin
(Dako). Staining was completed after incubation with diaminobenzidine (DAB) substrate-chromogen solution (Vector Laboratories, Burlingame, Calif., USA), counterstained with haematoxylin and then mounted in aqueous mounting media. We compared the relative intensity of immunostaining in normal and diabetic rats on the same slide to avoid discrepancies of tissue thickness and processing times. Positive controls for nNOS and eNOS immunohistochemical studies were carried out and showed that nNOS and eNOS immunoreactive stainings were noted in the neuron of the hypothalamus and the endothelium of the pulmonary artery, respectively (results not shown). Negative controls included non-immune rabbit serum, and nNOS and eNOS antibodies preabsorbed with an excess of anti-nNOS and anti-eNOS blocking peptides (CalbiochemNovabiochem). The nNOS and eNOS immunostaining intensities were graded according to the following scale: " 0 " = no staining, " $1 "=$ weak staining, " $2 "=$ moderate staining, and " 3 " = strong staining. The intensity was determined in 10 glomeruli, 10 tubular segments and 10 blood vessels per animal and expressed as the average intensity per tubules, glomeruli and blood vessels. The intensity and distribution of nNOS and eNOS immunostaining were evaluated by two nephrologists without prior knowledge of the source of the sections.

Sequencing of the renal NOS $c D N A$. The cDNA of nNOS was amplified by PCR. The amplified DNA fragments were then purified by Chroma spin DNA purification column (Clontech Lab, Palo Alto, Calif., USA). According to Sanger's enzymatic method, the purified PCR products were directly sequenced using chain terminating dideoxynucleotides and a double strand DNA cycle sequencing system (BRL, Life Technologies, Gaithersburg, Mo., USA). Sequencing reactions were denatured for $3 \mathrm{~min}$ at $95^{\circ} \mathrm{C}$, and loaded onto a $41 \mathrm{~cm}$ denaturing Long-Ranger gel (AT Biochem, Malvern, Pa., USA), and electrophoresed on a LI-COR model 4200 automated DNA sequencer (LI-COR, Biotechnology Division, Neb., USA).

Extraction of renal tissues and plasma. Right kidneys were minced and boiled for $5 \mathrm{~min}$ in $10 \mathrm{vol} 0.1 \mathrm{~mol} / \mathrm{l}$ acetic acid. Once cooled to $4{ }^{\circ} \mathrm{C}$, the acid tissues were homogenized with a Polytron homogenizer (Janke \& Kunkel IK A-Labortechnik, Staufen, Germany) for $60 \mathrm{~s}$. The homogenates were centrifuged at $4500 \mathrm{rev} / \mathrm{min}$ for $40 \mathrm{~min}$ at $4{ }^{\circ} \mathrm{C}$. The acid supernatants were then extracted using Sep-Pak $\mathrm{C}_{18}$ cartridges (Water Associates, Milford, Mass., USA) that had been pre-wetted with $4 \mathrm{ml}$ of $60 \%$ acetonitrile (ACN) in $0.1 \%$ trifluoacetic acid (TFA). The cartridges with the absorbed peptides were then washed with $6 \mathrm{ml}$ of $0.1 \%$ TFA and eluted with $3 \mathrm{ml}$ of $60 \%$ ACN in $0.1 \%$ TFA. Plasma samples were also extracted using Sep-Pak $\mathrm{C}_{18}$ cartridges using the same method as described for renal tissues. The elutes were lyophilised and reconstituted for radioimmunoassay.

Assay methods. Angiotension II, vasopressin and ANP immunoreactivities from samples of plasma and angiotensin II from renal tissues were determined by RIA methods after lyophilisate was resuspended in RIA buffer. Concentrations of plasma and urinary sodium and osmolality were determined in an automatic analyzer (Nova Biochemical, Newton, Mass., USA). Urinary $\mathrm{NO}_{2}^{-} / \mathrm{NO}_{3}^{-}$was measured using Griess reagent. Briefly, samples were incubated with nitrate reductase in the presence of NADPH to reduce all nitrate to nitrite. After the incubation, total $\mathrm{NO}_{2}$ in the samples was measured using the Griess reagent and measured at $540 \mathrm{~nm}$. Known concentrations of $\mathrm{NaNO}_{2}$ were used to create a standard curve. 

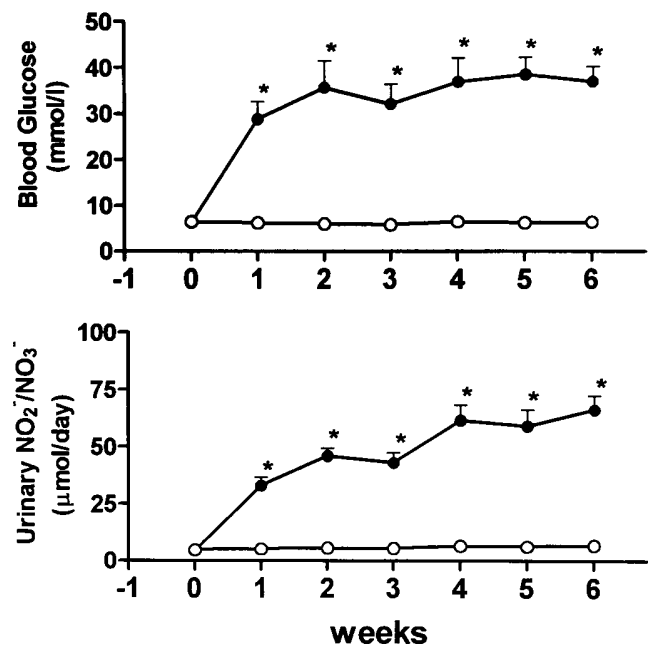

Fig.1. Mean plasma glucose values and urinary $\mathrm{NO}_{2}{ }^{-} / \mathrm{NO}_{3}{ }^{-} \mathrm{ex}-$ cretion rate before and $1,2,3,4,5$ and 6 weeks after the injection of streptozotocin or citric buffer in 12 normal control (○) and 12 diabetic (O) rats. ${ }^{*} p<0.001$ vs control group
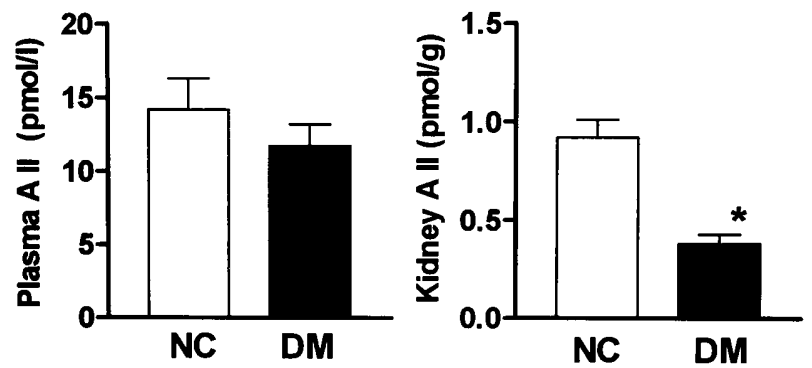

Fig. 2. Plasma angiotensin II (A II) and kidney angiotensin II content. Effect of diabetes on plasma angiotensin II concentration (left) and kidney angiotensin II content (right) in 12 normal control (NC) and 12 diabetic (DM) rats. ${ }^{*} p<0.05$ vs normal control

Statistical analysis. The data are expressed as means \pm SEM. To test the difference between the two groups, two-tailed unpaired Student's $t$ test was used. We also carried out analysis of variance to test the difference among multiple groups. If a difference was found, the Bonferroni test was used for comparison between two groups. A $p$ value of less than 0.05 was considered statistically significant.

\section{Results}

Metabolic data and urinary $\mathrm{NO}_{2}^{-} / \mathrm{NO}_{3}^{-}$. The blood glucose and urinary $\mathrm{NO}_{2}{ }^{-} / \mathrm{NO}_{3}^{-}$excretion rate of 12 normal and 12 diabetic rats on week $0,1,2,3,4,5$ and 6 are shown in Figure 1. Plasma angiotensin II and kidney angiotensin II content are shown in Figure 2. Other biochemical and physical data on the 42nd day are shown in Table 1. In the diabetic group, the mean blood glucose concentrations from week 1 to 6 were significantly increased, and the daily water intake and urine amount increased noticeably com-
Table 1. Characteristics of normal control (NC) and diabetic (DM) rats on the 42 nd study day

\begin{tabular}{lll}
\hline & NC & DM \\
\hline$n$ & 12 & 12 \\
Body weight $(\mathrm{g})$ & $362 \pm 4.8$ & $238 \pm 5.6^{\mathrm{a}}$ \\
Kidney weight/body weight $\left(\mathrm{g} / \mathrm{g} \times 10^{-2}\right)$ & $0.38 \pm 0.01$ & $0.67 \pm 0.01^{\mathrm{a}}$ \\
Urine volume (ml/day) & $22 \pm 1.5$ & $153 \pm 6.8^{\mathrm{a}}$ \\
Water intake (ml/day) & $30 \pm 1.0$ & $172 \pm 6.2^{\mathrm{a}}$ \\
Plasma osmolality (mosmol/kg) & $287 \pm 3.3$ & $302 \pm 3.3^{\mathrm{b}}$ \\
Plasma sodium (mmol/l) & $140 \pm 2.6$ & $138 \pm 2.1$ \\
Plasma ANP (pmol/l) & $9.8 \pm 1.2$ & $18.8 \pm 1.6^{\mathrm{a}}$ \\
Plasma vasopressin (pmol/l) & $4.0 \pm 0.5$ & $6.3 \pm 0.8^{\mathrm{c}}$ \\
Urine sodium (mmol/day) & $0.92 \pm 0.06$ & $1.85 \pm 0.12^{\mathrm{a}}$ \\
Urine glucose (mmol/day) & 0 & $75 \pm 7.3^{\mathrm{a}}$ \\
Urine osmolality (mosmol/kg) & $18.3 \pm 3.5$ & $155.2 \pm 9.9^{\mathrm{a}}$ \\
\hline
\end{tabular}

Values are means \pm SEM. ${ }^{\mathrm{a}} p<0.001 ;{ }^{\mathrm{b}} p<0.01 ;{ }^{\mathrm{c}} p<0.05 \mathrm{vs}$ normal control (two-tailed unpaired Student's $t$ test)

Table 2. Relative tissue nNOS, eNOS, renin and angiotensinogen mRNA levels in the renal cortex, outer and inner medulla of 12 normal control rats

\begin{tabular}{lllll}
\hline & nNOS & eNOS & Renin & $\begin{array}{l}\text { Angiotensi- } \\
\text { nogen }\end{array}$ \\
\hline $\begin{array}{l}\text { Cortex } \\
\begin{array}{l}\text { Outer } \\
\text { medulla }\end{array}\end{array}$ & $1.00 \pm 0.08$ & $1.00 \pm 0.12$ & $1.00 \pm 0.06$ & $1.00 \pm 0.10$ \\
$\begin{array}{l}\text { Inner } \\
\text { medulla }\end{array}$ & $3.08 \pm 0.12$ & $1.82 \pm 0.13^{\mathrm{a}}$ & $0.18 \pm 0.08^{\mathrm{a}}$ & $1.38 \pm 0.08^{\mathrm{a}}$ \\
\hline
\end{tabular}

Values are means \pm SEM; mRNA levels of renal cortex in the normal control group were arbitrarily defined as 1.0 , and the relative levels of tissue nNOS, eNOS, renin and angiotensinogen mRNA levels in the renal outer medulla and inner medulla with the corresponding level in the renal cortex are shown. ${ }^{\mathrm{a}} p<0.001,{ }^{\mathrm{b}} p<0.05$ vs cortex; ${ }^{\mathrm{c}} p<0.001$ vs outer medulla (ANOVA, Bonferroni test)

pared with the corresponding values of normal rats. Compared with the normal rats, the diabetic group showed a significant decrease in body weight but a significant increase in mean kidney weight to body weight ratio. In the untreated diabetic rats, plasma ANP, vasopressin and osmolality as well as urinary sodium, glucose and osmolality excretion rate were increased, but plasma sodium concentrations showed no significant difference. Also, kidney angiotensin II content was significantly decreased and plasma angiotensin II showed some suppression but was not significantly different. As shown in Figure 1, the mean daily urinary $\mathrm{NO}_{2}{ }^{-} / \mathrm{NO}_{3}{ }^{-}$excretion rate was significantly increased at week 1 after diabetic induction and remained high for the entire 6-week study period in diabetic rats as compared with normal rats.

Neuronal and endothelial NOS mRNA in the kidney. The sequence of nNOS PCR product from the outer medulla was confirmed by chain terminating dideoxynucleotides and double strand DNA cycle sequencing system. The nNOS PCR product showed 

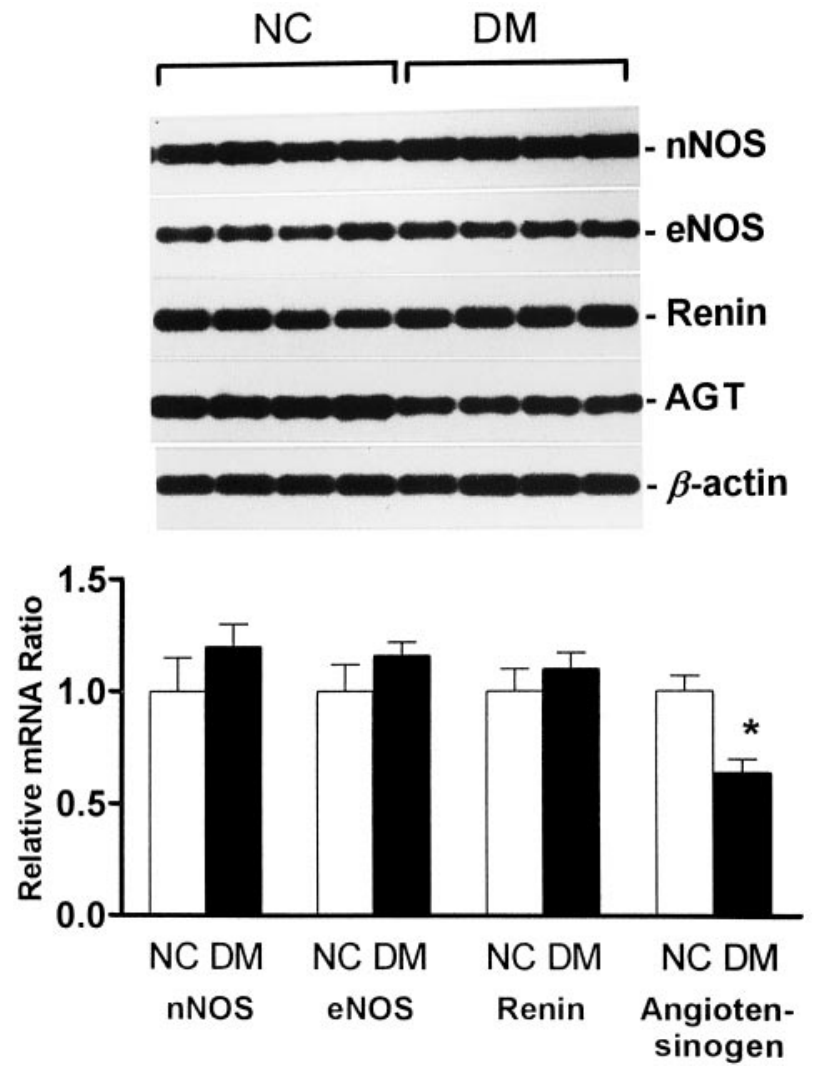

Fig.3. Amplification of nNOS, eNOS, renin, angiotensinogen (AGT) and $\beta$-actin mRNA in the renal cortex. Upper panel: autoradiographs of the amplification of nNOS, eNOS, renin, angiotensinogen and $\beta$-actin mRNA by RT-PCR followed by Southern blot hybridisation in renal cortex from four representative normal (NC) and four representative diabetic (DM) rats on the 42nd study day. Each lane represents an individual rat. Lower panel: relative ratios (means \pm SEM) of the densitometry readings for RT-PCR amplification between nNOS, eNOS, renin, angiotensinogen and $\beta$-actin in the renal cortex from $12 \mathrm{NC}$ and $12 \mathrm{DM}$ rats. $* p<0.05$ vs NC

$100 \%$ nucleotide identity to rat brain [26]. In Table 2, the relative levels of nNOS, eNOS, renin and angiotensinogen PCR product among renal cortex, outer and inner medulla are expressed as percentages of the mean densitometric values obtained from renal cortex. These data show that the greatest level of nNOS mRNA was found in the inner medulla, eNOS mRNA in the outer and inner medulla, renin mRNA in the renal cortex and angiotensinogen mRNA in the outer medulla.

Figure 3 (upper panel) shows the autoradiographs of RT-PCR amplification of nNOS, eNOS, renin, angiotensinogen and $\beta$-actin mRNA in the renal cortex from four representative normal and four representative diabetic rats on day 42 . The relative ratios of the densitometry measure of PCR products for nNOS, eNOS, renin and angiotensinogen mRNA with those for $\beta$-actin mRNA in the renal cortex from 12 control and 12 diabetic rats are shown in the lower panel of Figure 3. The relative ratios of cDNA product for
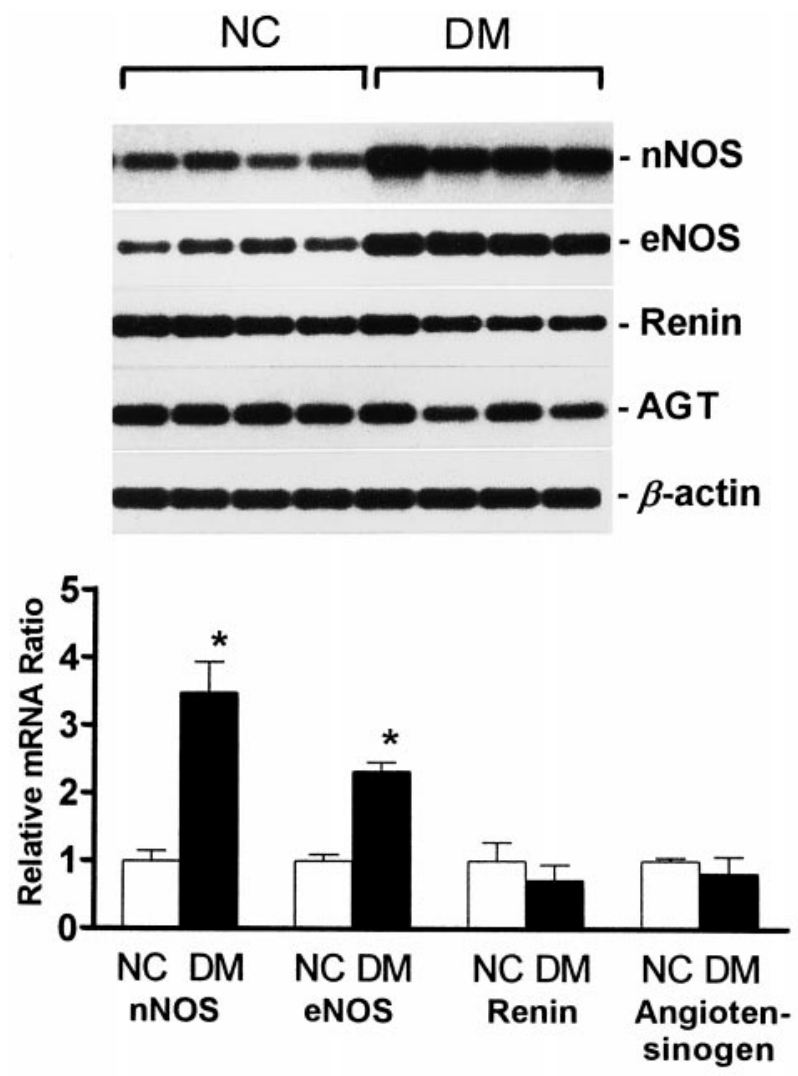

Fig. 4. Amplification of nNOS, eNOS, renin, angiotensinogen (AGT) and $\beta$-actin mRNA in the renal outer medulla. Upper panel: autoradiographs of the amplification of nNOS, eNOS, renin, angiotensinogen and $\beta$-actin mRNA by RT-PCR followed by Southern blot hybridisation in renal outer medulla from four representative normal (NC) and four representative diabetic (DM) rats on the 42nd study day. Each lane represents an individual rat. Lower panel: relative ratios (means \pm SEM) of the densitometry readings for RT-PCR amplification between nNOS, eNOS, renin, angiotensinogen and $\beta$-actin in the renal outer medulla from $12 \mathrm{NC}$ and $12 \mathrm{DM}$ rats. $* p<0.001$ vs NC

nNOS, eNOS, and renin mRNA with $\beta$-actin mRNA were not significantly different in the normal and diabetic rats, whereas the diabetic group showed a significant decrease in angiotensinogen $/ \beta$-actin cDNA ratio. The autoradiographs of RT-PCR amplification of nNOS, eNOS, renin, angiotesinogen and $\beta$-actin mRNA in the renal outer and inner medulla from four representative normal and four representative diabetic rats on day 42 are shown in the upper panels of Fig. 4 and Fig. 5, respectively. The relative ratios of the densitometry measure of PCR products for nNOS, eNOS, renin and angiotensinogen mRNA with the corresponding levels for $\beta$-actin in the renal outer and inner medulla from 12 normal and 12 diabetic rats are shown in the lower panels of Figures 4 and 5, respectively. The relative ratios of cDNA product for nNOS and eNOS mRNA with $\beta$-actin mRNA in the outer medulla of diabetic rats was significantly increased, whereas neither renin nor angiotensinogen 

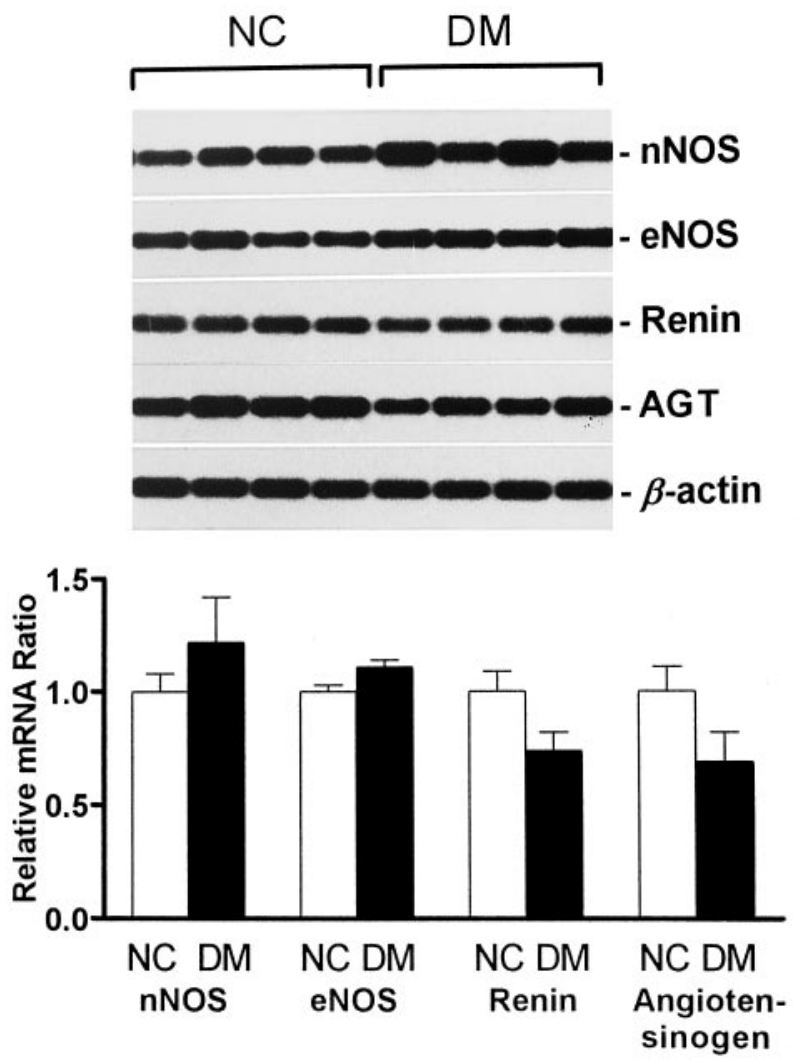

Fig.5. Amplification of nNOS, eNOS, renin, angiotensinogen (AGT) and $\beta$-actin mRNA in the renal inner medulla. Upper panel: autoradiographs of the amplification of nNOS, eNOS, renin, angiotensinogen and $\beta$-actin mRNA by RT-PCR followed by Southern blot hybridisation in renal inner medulla from four representative normal (NC) and four representative diabetic (DM) rats on the 42nd study day. Each lane represents an individual rat. Lower panel: relative ratios (means \pm SEM) of the densitometry readings for RT-PCR amplification between nNOS, eNOS, renin, angiotensinogen and $\beta$-actin in the renal inner medulla from $12 \mathrm{NC}$ and $12 \mathrm{DM}$ rats

mRNA were significantly different between normal and diabetic rats. In the renal inner medullary tissues, the relative ratios of nNOS, eNOS, renin and angiotensinogen cDNA product with these corresponding $\beta$-actin values showed no significant difference between normal and diabetic rats.

Staining for $n N O S$ and eNOS protein. In normal rats (Table 3), immunohistochemical studies showed positive nNOS and eNOS immunostaining in almost all segments of renal tubule. Neuronal NOS and eNOS immunoreactive staining were moderate in proximal straight tubule (PST), MTAL, distal convoluted tubule (DCT), cortical collecting duct (CCD), outer medullary collecting duct (OMCD), and inner modullary collecting duct (IMCD). The glomeruli, PCT, and blood vessels of the control rats showed weak staining for eNOS. Very weak staining for eNOS in the thin limb of Henle's loop (TL) and for nNOS in glomeruli, PCT, TL and blood vessels was found.
Table 3. The immunoreactive intensity of neuronal nitric oxide synthase (nNOS) and endothelial NOS (eNOS) as determined by immunohistochemistry in four normal control rats

\begin{tabular}{lll}
\hline & nNOS & eNOS \\
\hline Glomerulus & $0.53 \pm 0.09$ & $1.13 \pm 0.06^{\mathrm{c}}$ \\
PCT & $0.48 \pm 0.08$ & $0.73 \pm 0.10$ \\
PST & $1.93 \pm 0.08^{\mathrm{a}}$ & $1.80 \pm 0.11^{\mathrm{a}}$ \\
TL & $0.37 \pm 0.08$ & $0.38 \pm 0.08$ \\
MTAL & $2.15 \pm 0.08^{\mathrm{a}, \mathrm{b}}$ & $2.10 \pm 0.07^{\mathrm{a}, \mathrm{b}}$ \\
DCT & $1.73 \pm 0.08^{\mathrm{a}}$ & $1.48 \pm 0.10^{\mathrm{c}}$ \\
CCD & $1.87 \pm 0.07^{\mathrm{a}}$ & $1.93 \pm 0.09^{\mathrm{a}, \mathrm{b}}$ \\
OMCD & $1.85 \pm 0.06^{\mathrm{a}}$ & $2.10 \pm 0.08^{\mathrm{a}, \mathrm{b}}$ \\
IMCD & $1.86 \pm 0.09^{\mathrm{a}}$ & $2.38 \pm 0.09^{\mathrm{a}, \mathrm{b}, \mathrm{d}}$ \\
Blood vessel & $0.20 \pm 0.06$ & $1.15 \pm 0.06^{\mathrm{c}}$ \\
\hline
\end{tabular}

PCT: proximal convoluted tubule; PST: proximal straight tubule; TL: thin limb of Henle's loop; MTAL: medullary thick ascending limb; DCT: distal convoluted tubule; CCD: cortical collecting duct; OMCD: outer medullary collecting duct; IMCD: inner medullary collecting duct. The nNOS and eNOS immunostaining intensity was graded on the following scale: " 0 " = no immunostaining; " 1 " = weak staining; " 2 " = moderate staining; and " 3 " = strong staining. " $p<0.001$ vs Glomeruli, PCT, TL and blood vessel; ${ }^{\mathrm{b}} p<0.05$ vs DCT; ${ }^{\mathrm{c}} p<0.05$ vs TL and PCT; ${ }^{\mathrm{d}} p<0.05$ vs CCD and PST (ANOVA, Bonferroni test)

Figure 6 shows the results of immunohistochemical studies for nNOS in the renal cortex, outer and inner medulla from one representative normal and diabetic rats; Figure 7 shows results for eNOS. Figure 8 shows the changes of nNOS and eNOS immunoreactive intensity in diabetic rats in comparison to normal rats. Diabetic rats had a similar distribution pattern of immunostaining intensity. There was, however, a considerable increase in intensity of immunostaining for nNOS and eNOS in PST and MTAL but only a mild increase for nNOS in DCT, CCD, OMCD and IMCD and for eNOS in PCT and DCT compared with normal control rats. No immunoreactive labelling was observed when the sections were incubated with preabsorbed antibodies (shown in Fig. 6 and 7 I-L) or with rabbit normal serum in the absence of primary antibody.

Fig.6. Immunohistochemical staining for neuronal NOS (nNOS) in the same paraffin section of one representative normal control (left panel) and one representative diabetic (middle panel) rats. $(\mathbf{A}),(\mathbf{B}),(\mathbf{C})$ and $(\mathbf{D})$ are tissue sections from renal cortex, outer stripe and inner stripe of outer medulla, and inner medulla of one normal control rat, whereas $(\mathbf{E})$, $(\mathbf{F}),(\mathbf{G})$ and $(\mathbf{H})$ are the corresponding tissue sections from one diabetic rat. $(\mathbf{I}),(\mathbf{J}),(\mathbf{K})$ and $(\mathbf{L})$ show negative control (nNOS antibody pre-absorbed with blocking peptides) from one normal rat. Long arrow: proximal convoluted tubule; asterisks: distal convoluted tubule; short arrow: proximal straight tubule; short hollow arrow: medullary thick ascending limb; arrowhead: inner medullary collecting duct. Magnification: $\mathbf{A}, \mathbf{E}$, $\mathbf{I} \times 180 ; \mathbf{B}-\mathbf{D}, \mathbf{F}-\mathbf{H}, \mathbf{J}-\mathbf{L} \times 360$ 

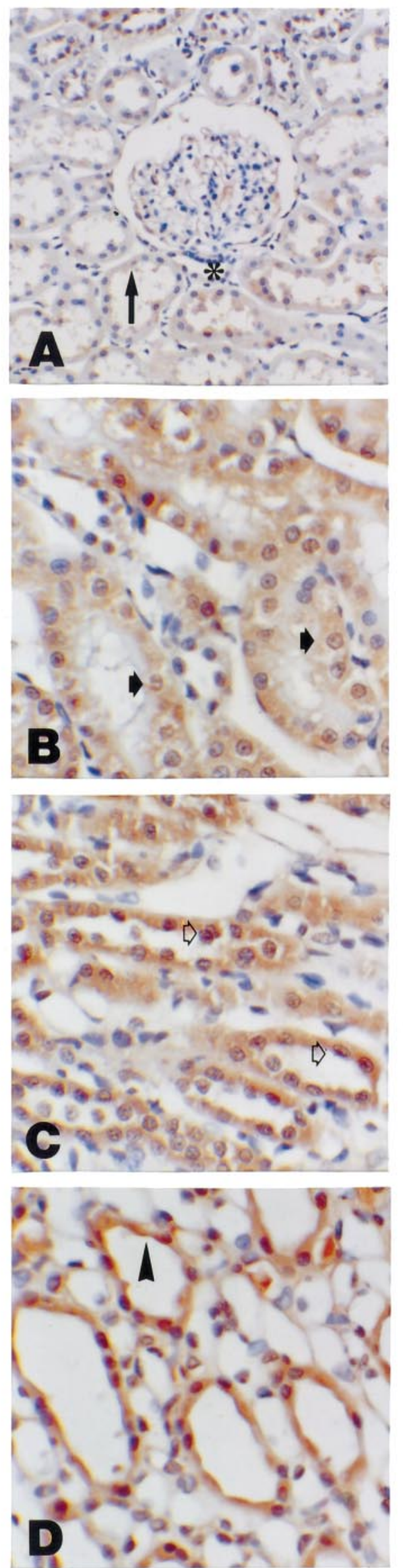
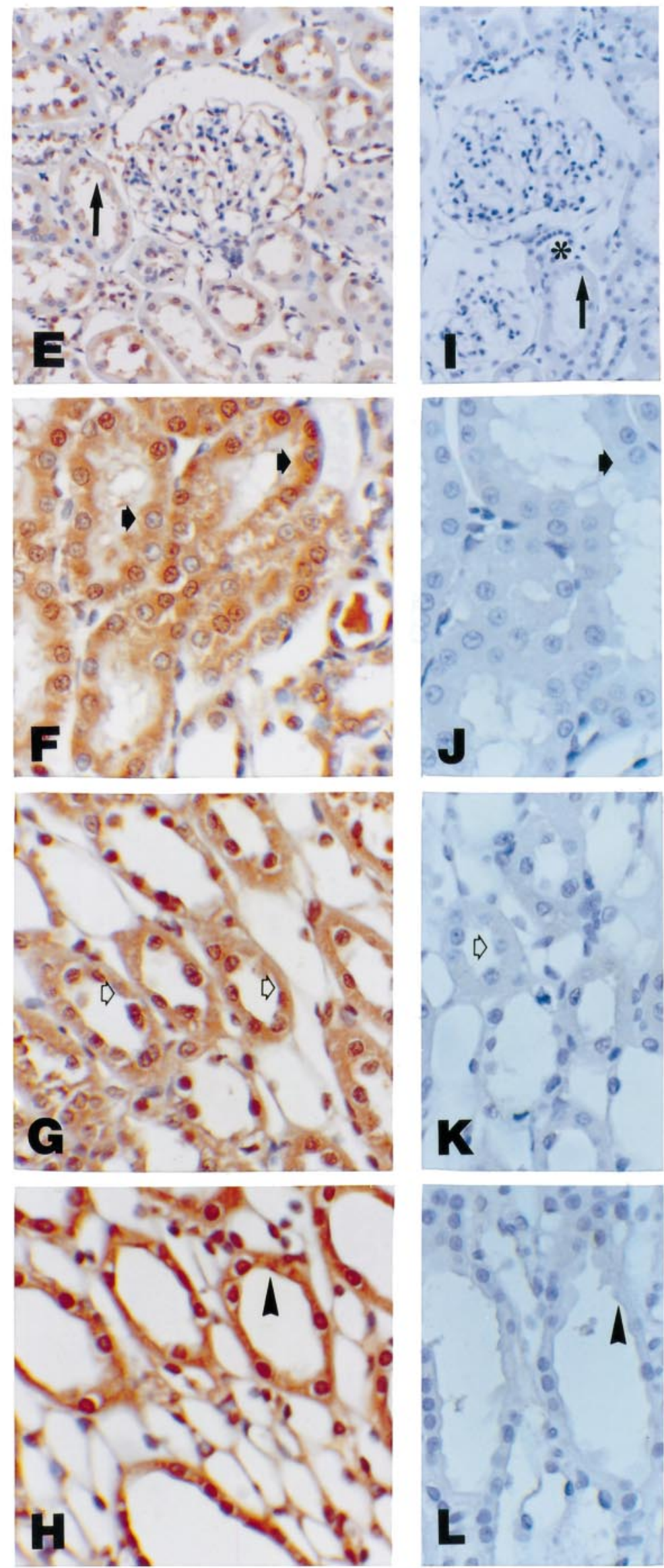

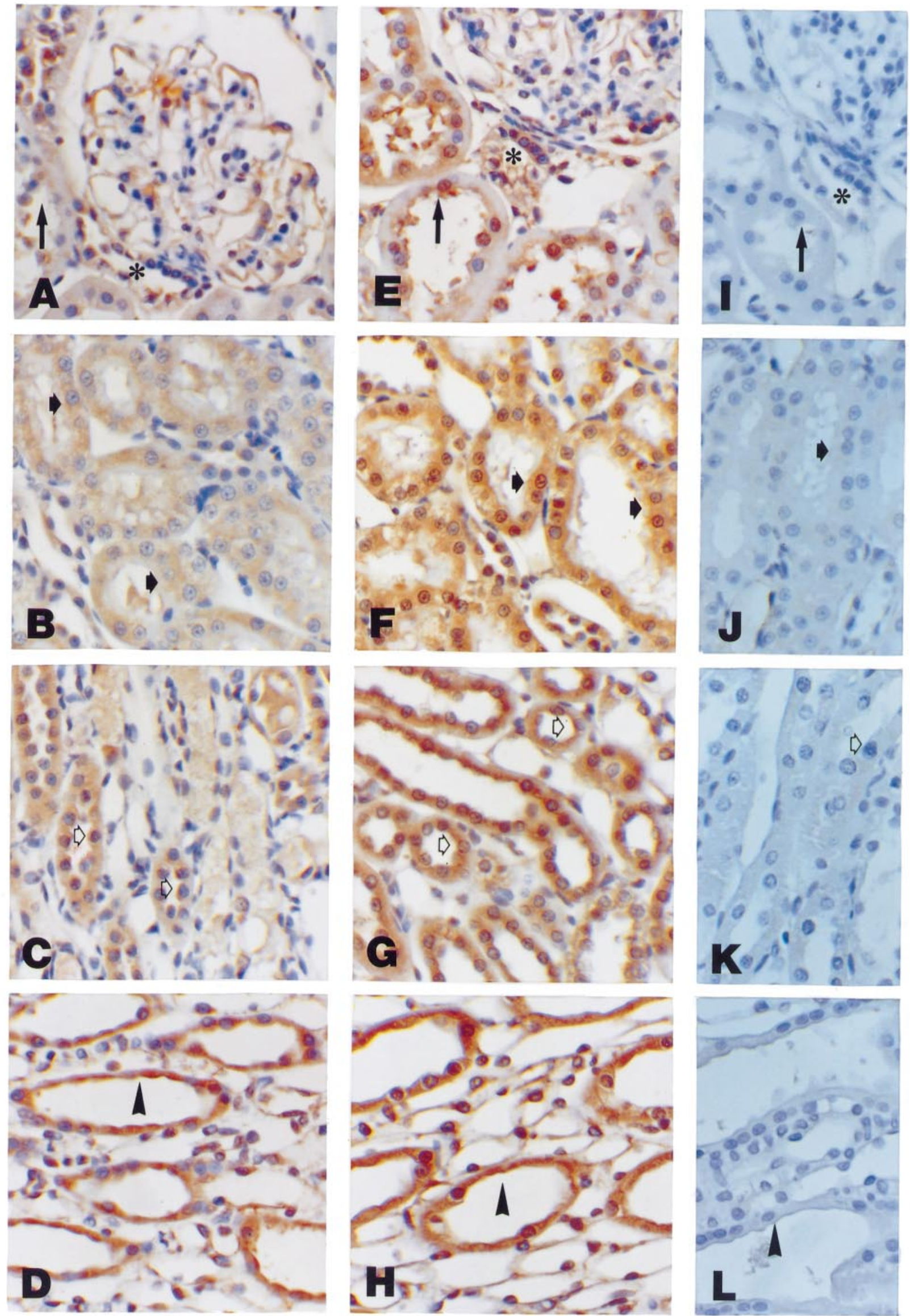
Fig.7. Immunohistochemical staining for endothelial NOS (eNOS) in the same paraffin section of one representative normal control (left panel) and one representative diabetic (middle panel) rats. $(\mathbf{A}),(\mathbf{B}),(\mathbf{C})$ and $(\mathbf{D})$ are tissue sections from renal cortex, outer stripe and inner stripe of outer medulla, and inner medulla of one normal control rat, whereas $(\mathbf{E})$, $(\mathbf{F}),(\mathbf{G})$ and $(\mathbf{H})$ are the corresponding tissue sections from one diabetic rat. (I), (J), (K) and (L) show negative control (eNOS antibody pre-absorbed with blocking peptides) on the corresponding tissue sections from one normal rat. Long arrow: proximal convoluted tubule; asterisks: distal convoluted tubule; short arrow: proximal straight tubule; hollow short arrow: medullary thick ascending limb; arrowhead: inner medullary collecting duct. Magnification: A-L $\times 360$

\section{Discussion}

Our study shows that endothelial and neuronal nitric oxide synthase expression is considerably increased in the kidneys of diabetic rats, particularly in the renal medulla. This conclusion is based on the following three findings: 1) nNOS and eNOS mRNA expression was significantly increased in the renal outer medulla of diabetic rats, 2) the intensities of immunostaining for nNOS and eNOS in PST and MTAL were distinctively increased, whereas nNOS in DCT, CCD, OMCD, IMCD and eNOS in PCT, DCT were slightly increased in diabetic rat kidneys, 3) urinary $\mathrm{NO}_{2}^{-} / \mathrm{NO}_{3}^{-}$excretion rates were significantly increased after the injection of streptozotocin.

Several studies using RT-PCR and in situ hybridization have shown the presence of neuronal NOS mRNA in the collecting ducts, thick ascending limb of Henle's loop, vasa recta, glomeruli, and renal nerves $[15,27]$ and eNOS mRNA in proximal tubules, thick ascending limbs, collecting ducts, glomerulus, and preglomerular vasculature [27, 28]. Using the immunohistochemical technique, nNOS immunoreactive staining in MTAL, PST, CCD, IMCD, OMCD, and DCT of our normal rats was significantly higher than in PCT, glomeruli, thin limbs of Henle's loop and blood vessels. Endothelial NOS immunoreactive staining in IMCD, MTAL, PST, OMCD and CCD was higher than in glomeruli, PCT, DCT, thin limb of Henle's loop and blood vessels. All of these studies, including ours, have clearly indicated that renal nephron tubules are very important sites in the synthesis of nitric oxide.

Several vasoactive substances $[1-9,29,30]$ have been found to affect renal haemodynamic alterations which have been thought to play a part in the initiation and progression of diabetic nephropathy. The synthesis of prostaglandin [1], kinin [2], and ANP [3] have been reported to be increased in the kidneys of diabetic rats, and it has been proposed that this synthesis leads to an increase in the glomerular filtration rate. A large number of investigations [4-9] have re-
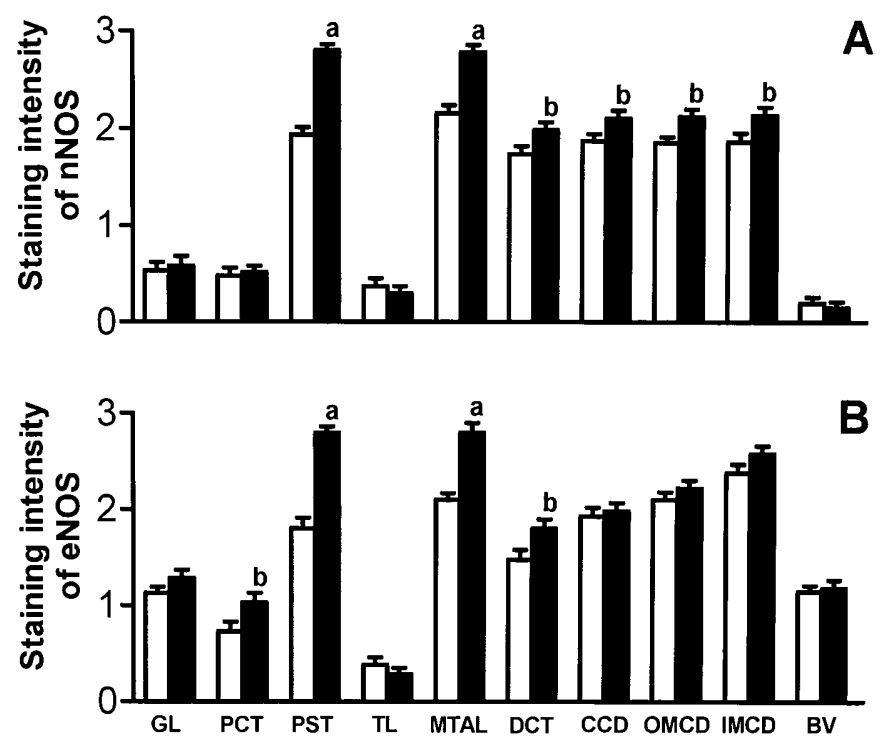

Fig. 8. Expression of neuronal NOS (A) and endothelial NOS (B) immunoreactive staining as determined by immunohistochemistry in four normal control $(\square)$ and four diabetic ( $\square$ ) rats. $0=$ no detectable staining; $1=$ weak staining; $2=$ moderate staining; $3=$ strong staining. ${ }^{\mathrm{a}} p<0.001,{ }^{\mathrm{b}} p<0.05$ vs normal control (unpaired Student's $t$ test)

ported that urinary $\mathrm{NO}_{2}{ }^{-} / \mathrm{NO}_{3}{ }^{-}$excretion rates are significantly higher in diabetic rats than those found in normal rats. It has also been confirmed that the increase of renal NO synthesis is responsible for the increase of the urinary $\mathrm{NO}_{2}^{-} / \mathrm{NO}_{3}^{-}$excretion rate [4]. Increased renal NO synthesis is also thought to be involved in glomerular hyperfiltration in experimental diabetic rats. Using immunohistochemical staining, the expression of eNOS in afferent arterioles and glomeruli of diabetic rats was reported to be increased compared with normal rats [9]. Additionally, it was also found that three isoforms of NOS (nNOS, eNOS and iNOS), determined by Western blot analysis, were all increased in the cortex, whereas they remained unaltered in the medulla on the 7th day after streptozotocin-induced diabetes [11]. Our results in this pioneer study show, however, that nNOS and eNOS mRNA expression in the renal outer medulla were appreciably increased in diabetic rats. Furthermore, nNOS immunostaining in PST, MTAL, DCT, CCD, OMCD and IMCD, and eNOS immunostaining in PST, MTAL, PCT and DCT as well as urinary $\mathrm{NO}_{2}{ }^{-} / \mathrm{NO}_{3}{ }^{-}$excretion rates were significantly increased after the induction of diabetes. Our findings indicate that NO synthesis is increased in the kidneys of diabetic rats.

A large number of studies have shown that the renal medulla has a greater capacity to generate NO than the renal cortex. It was reported that the basal NOS activity in the medulla is three times greater than that in the renal cortex [12]. The medullary thick ascending limb has been found to have the greatest 
NADPH-dependent diaphorase staining of any nephron segment in the rats [13]. Additionally, it has been shown that there are greater amounts of different NOS proteins in the rat medulla than in the renal cortex [14]. Using RT-PCR, fairly high levels of nNOS mRNA in IMCD [15] and iNOS mRNA in the MTAL [16] and IMCD [16, 17] were reported with lesser expression in other renal tubular segments or vasa recta. As in these studies, we also found that the relative levels of nNOS and eNOS mRNA in renal medulla of normal rat kidney were significantly higher when compared with corresponding levels found in the renal cortex. Also, in the current study, nNOS and eNOS mRNA levels were found to have increased 3.5-fold and 1.8-fold in the outer medulla of diabetic kidneys compared with normal rats. There was, however, no significant difference found in the levels of nNOS and eNOS mRNA in the renal cortex and inner medulla between diabetic and normal groups. Additionally, the greatest enhancement of nNOS and eNOS immunoreactive staining was found in PST and MTAL of diabetic rats. The greater enhancement of nNOS and eNOS synthesis in the renal outer medulla of diabetic rats might imply that the outer medullary NOS has a relatively strong responsiveness to hyperglycaemia in diabetic rats.

In this study, the injection of streptozotocin caused considerable plasma hyperosmolality as well as increased plasma vasopressin concentrations after hyperglycaemia and polyuria occurred in our diabetic rats. Increased plasma ANP concentration and unchanged plasma angiotensin II, however, were also observed in these diabetic rats. Recently, the interaction between renal angiotensin and NO production has been widely studied $[31,32]$. The systemic and intrarenal renin-angiotensin system during sodium depletion has been reported to be activated along with an increase of renal NO production through the stimulation of angiotensin II at the angiotensin $\mathrm{AT}_{2}$ receptor [32]. Our diabetic animals, however, showed suppressed plasma angiotensin II concentration and renal angiotensin II content in conjunction with unchanged renal renin mRNA and decreased cortical angiotensinogen mRNA expression. Therefore, it seemed improbable that the upregulation of NOS expression was caused by renin-angiotensin activation in our diabetic rats. Similarly, several studies have shown that the production of renal NO [33] and prostaglandin [34] are also noticeably enhanced through the stimulation of vasopressin. In our diabetic rats, the increase of vasopressin was accompanied by the enhanced expression of intra-renal NOS-NO pathway. It has been reported that expression of nNOS gene in the hypothalamic paraventricular and supraoptic nuclei is increased by osmotic stimuli such as dehydration and salt loading [35, 36]. More recently, upregulation of hypothalamic $n N O S$ gene was also found in experimental diabetic rats and it is suggested that this increase is caused by plasma hyperosmolality and hyperglycaemia [37]. All these findings allow us to hypothesize that increased vasopressin or plasma hyperosmolality possibly stimulates renal nitric oxide synthesis in diabetic rats. Further studies are needed to clarify this assumption.

In summary, our results show that neuronal and endothelial NOS mRNA in the renal outer medulla, NOS immunoreactive protein in proximal straight tubule and medullary thick ascending limb were considerably enhanced in the face of hyperglycaemia and hyperosmolality in streptozotocin-induced diabetic rats. This study indicates that the increase in NOS expression in the kidney, particularly in the renal outer medulla, possibly participates in the renal regulatory pathways activated by diabetes.

Acknowledgements. This study was supported by grants NSC88-2314-B-037-057 from the National Science Council of the Republic of China. We are grateful to Ms. P. Chen, I.-H. Chen, H.-Y. Peng, C.-L. Chen, and S.-J. Lee for their expert technical assistance.

\section{References}

1. Craven PA, Caines MA, DeRubertis FR (1987) Sequential alterations in glomerular prostaglandin and thromboxane synthesis in diabetic rats: relationship to the hyperfiltration of early diabetes. Metabolism 36: 95-103

2. Jaffa AA, Chai KX, Chao J, Chao L, Mayfield RK (1992) Effects of diabetes and insulin on expression of kallikrein and renin genes in the kidney. Kidney Int 41: 789-795

3. Shin SJ, Lee YJ, Tan MS, Hsieh TJ, Tsai JH (1997) Increased atrial natriuretic peptide mRNA expression in the kidney of diabetic rats. Kidney Int 51: 1100-1105

4. Bank N, Aynedjian HS (1993) Role of EDRF (nitric oxide) in diabetic hyperfiltration. Kidney Int 43: 1306-1312

5. Komers R, Allen TJ, Cooper ME (1994) Role of endothelium-derived nitric oxide in the pathogenesis of the renal hemodynamic changes of experimental diabetes. Diabetes 43: $1190-1197$

6. Komers R, Cooper ME (1996) Renal sodium handling in experimental diabetes: role of NO. Nephrol Dial Transplant 11: 2170-2177

7. Mattar AL, Fujihara CK, Ribeiro MO, de Nucci G, Zatz R (1996) Renal effects of acute and chronic nitric oxide inhibition in experimental diabetes. Nephron 74: 136-143

8. Goor Y, Peer G, Iaina A et al. (1996) Nitric oxide in ischaemic acute renal failure of streptozotocin diabetic rats. Diabetologia 39: 1036-1040

9. Sugimoto H, Shikata K, Matsuda M et al. (1998) Increased expression of endothelial cell nitric oxide synthase (eNOS) in afferent and glomerular endothelial cells is involved in glomerular hyperfiltration of diabetic nephropathy. Diabetologia 41: 1426-1434

10. Yagihashi N, Nishida N, Geuk Seo H, Taniguchi N, Yagihashi S (1996) Expression of nitric oxide synthase in macula densa in streptozotocin diabetic rats. Diabetologia 39: 793-799

11. Choi KC, Kim NH, An MR, Kang DG, Kim SW, Lee JU (1997) Alterations of intrarenal renin-angiotensin and ni- 
tric oxide systems in streptozotocin-induced diabetic rats. Kidney Int 60: S23-S27

12. Mckee M, Scavone C, Nathanson JA (1994) Nitric oxide, cGMP, and hormone regulation of active sodium transport. Proc Natl Acad Sci USA 91: 12056-12060

13. Brezis M, Heyman SN, Dinour D, Epstein FH, Rosen S (1991) Role of nitric oxide in renal medullary oxygenation: Studies in isolated and intact rat kidneys. J Clin Invest 88: 390-395

14. Mattson DL, Higgins DJ (1996) Influence of dietary sodium intake on renal medullary nitric oxide synthase. Hypertension 27: 688-692

15. Terada Y, Tomita K, Nonoguchi H, Marumo F (1992) Polymerase chain reaction localization of constitutive nitric oxide synthase and soluble guanylate cyclase messenger RNAs in microdissected rat nephron segments. J Clin Invest 90: 659-665

16. Morrissey JJ, McCracken R, Kaneto H, Vehaskari M, Montani D, Klahr S (1994) Localization of an inducible nitric oxide synthase mRNA in the normal kidney. Kidney Int 45: 998-1005

17. Shin SJ, Lai FJ, Wen JD et al. (1999) Increased nitric oxide synthase mRNA expression in the medulla of water-deprived rats. Kidney Int 56: 2191-2202

18. Kone BC, Baylis C (1997) Biosynthesis and homeostatic roles of nitric oxide in the normal kidney. Am J Physiol 272: F561-F578

19. Thorup C, Persson AEG (1994) Inhibition of locally produced nitric oxide resets tubuloglomerular feedback mechanism. Am J Physiol 267: F606-F611

20. Wilcox CS, Welch WJ, Murad F et al. (1992) Nitric oxide synthase in macula densa regulates glomerular capillary pressure. Proc Natl Acad Sci USA 89: 11993-11997

21. Fenoy FJ, Ferrer P, Carbonell L, Garcia-Salom M (1995) Role of nitric oxide on papillary blood flow and pressure natriuresis. Hypertension 25: 408-414

22. Chomczynski P, Sacchi N (1987) Single-step method of RNA isolation by acid guanidium thiocyanate-phenolchloroform extraction. Anal Biochem 162: 156-159

23. Singh I, Grams M, Wang WH et al. (1996) Coordinate regulation of renal expression of nitric oxide synthase, renin, and angiotensinogen mRNA by dietary salt. Am J Physiol 270: F1027-F1037

24. Shin SJ, Wen JD, Chen IH et al. (1998) Increased renal ANP synthesis but decreased or unchanged cardiac ANP synthesis in water-deprived and salt-restricted rats. Kidney Int 54: 1617-1625

25. Lan HY, Mu W, Nikolic-Paterson DJ, Atkins RC (1995) A novel, simple, reliable, and sensitive method for mutiple immunoenzyme staining: use of microwave oven heating to block antibody crossreactivity and retrieve antigens. J Histochem Cytochem 43: 97-102

26. Bredt DS, Hwang PM, Glatt CE, Lowenstein C, Reed RR, Snyder SH (1991) Cloned and expressed nitric oxide synthase structurally resembles cytochrome P-450 reductase. Nature 351: 714-718

27. Bachmann S, Bosse HM, Mundel P (1995) Topography of nitric oxide synthesis by localizing constitutive NO synthases in mammalian kidney. Am J Physiol 268: F885-F898

28. Ujiie K, Yuen J, Hogarth L, Danziger R, Star RA (1994) Localization and regulation of endothelial NO synthase mRNA expression in rat Kidney. Am J Physiol 267: F296-F302

29. Correa-Rotter R, Hostetter TH, Rosenberg ME (1992) Renin and angiotensinogen gene expression in experimental diabetes mellitus. Kidney Int 41: 796-804

30. Fukui M, Nakamura T, Ebihara I et al. (1993) Gene expression for endothelin and their receptors in glomeruli of diabetic rats. J Lab Clin Med 122: 149-156

31. De Nicola L, Blantz RC, Gabbai FB (1992) Nitric oxide and angiotensin II: glomerular and tubular interaction in the rat. J Clin Invest 89: 1246-1256

32. Siragy HM, Carey RM (1997) The subtype $2\left(\mathrm{AT}_{2}\right)$ angiotensin receptor mediates renal production of nitric oxide in conscious rats. J Clin Invest 100: 264-269

33. Park F, Zou AP, Cowley AW Jr (1998) Arginine vasopressin-mediated stimulation of nitric oxide within the rat renal medulla. Hypertension 32: 896-901

34. Kompanowska-Jezierska E, Emmeluth C, Grove L, Christensen P, Sadowski J, Bie P (1998) Mechanism of vasopressin natriuresis in the dog: role of vasopressin receptors and prostaglandins. Am J Physiol 274: R1619-R1625

35. Kadowaki K, Kishimoto J, Leng G, Emson PC (1994) Upregulation of nitric oxide synthase (NOS) gene expression together with NOS activity in the rat hypothalamo-hypophysial system after chronic salt loading: evidence of a neuromodulatory role of nitric oxide in arginine vasopressin and oxytocin secretion. Endocrinology 134: 1011-1017

36. Villar MJ, Ceccatelli S, Ronnqvist M, Hokfelt T (1994) Nitric oxide synthase increases in hypothalamic magnocellular neurons after salt loading in the rat. An immunohistochemical and in situ hybridization study. Brain Res 644: 273-281

37. Serino R, Ueta Y, Tokunaga M et al. (1998) Upregulation of hypothalamic nitric oxide synthase gene expression in streptozotocin-induced diabetic rats. Diabetologia 41: 640-648 